\title{
Impact of withholding early parenteral nutrition in adult critically ill patients on ketogenesis in relation to outcome
}

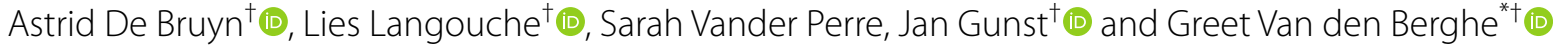

Withholding parenteral nutrition until one week after intensive care unit (ICU) admission (late-PN) was previously shown to accelerate recovery and reduce infections in critically ill adults and children, as compared to early supplementing insufficient enteral feeding with parenteral nutrition (early-PN) $[1,2]$. In a detailed secondary analysis of the pediatric PEPaNIC randomized controlled trial (RCT), we previously identified enhanced ketogenesis as potential mediator of part of this outcome benefit. Indeed, late-PN increased plasma concentrations of the ketone 3-hydroxybutyrate (3HB) up to sixfold, with a peak effect on day 2 [3]. Increased $3 \mathrm{HB}$ independently associated with an accelerated weaning from mechanical ventilation and a shorter time to live ICU discharge. These associations remained significant after adjusting for ketogenic regulators, suggesting a direct mediator role [3].

In this secondary analysis of patients included in the EPaNIC RCT $(n=4640)$, we studied whether late-PN had a similar impact on ketones in critically ill adults as compared with early-PN, and whether this may have mediated its outcome benefits. To this purpose, we quantified plasma $3 \mathrm{HB}$ with an enzymatic assay [3] in the predefined subgroup of patients with a surgical contraindication to enteral nutrition [1]. In this subgroup (509/517 patients with available plasma), there was a larger difference in caloric intake than in the total study population (Fig. 1a), and the outcome benefits of late-PN appeared to be more pronounced [1] (Table1).

We first performed a time course analysis in a propensity-score-matched subset of 110 patients (Table 1), to study whether late-PN enhanced ketogenesis and to identify the day of maximal effect (if any) (Fig. 1b). In the matched subset, late-PN significantly increased plasma $3 \mathrm{HB}$ from day 1 until day 7 (all $P \leq 0.0013$ ), with a maximal effect on day 2. Subsequently, we quantified plasma $3 \mathrm{HB}$ on this day of maximal effect in all patients with a surgical contraindication to enteral nutrition. In these patients, late-PN significantly $(P<0.0001)$ increased plasma $3 \mathrm{HB}$. Thereafter, we studied a potential mediator role of this $3 \mathrm{HB}$ effect on time to live ICU discharge, live ICU discharge within 8 days, and incidence of new infection through multivariable Cox, respectively logistic regression analysis, adjusted for baseline risk factors (age, BMI, malignancy, APACHEII score, NRS score, diagnostic group). Plasma $3 \mathrm{HB}$ did not independently associate with time to live ICU discharge $(P=0.54)$, live ICU discharge within 8 days $(P=0.23)$ or incidence of new infection $(P=0.71)$.

\footnotetext{
*Correspondence: greet.vandenberghe@kuleuven.be

${ }^{\dagger}$ Astrid De Bruyn, Lies Langouche, Jan Gunst and Greet Van den Berghe have contributed equally to this work original author(s) and the source, provide a link to the Creative Commons licence, and indicate if changes were made. The images or other third party material in this article are included in the article's Creative Commons licence, unless indicated otherwise in a credit line to the material. If material is not included in the article's Creative Commons licence and your intended use is not permitted by statutory regulation or exceeds the permitted use, you will need to obtain permission directly from the copyright holder. To view a copy of this licence, visit http://creativecommons.org/licenses/by/4.0/. The Creative Commons Public Domain Dedication waiver (http://creativeco mmons.org/publicdomain/zero/1.0/) applies to the data made available in this article, unless otherwise stated in a credit line to the data. 


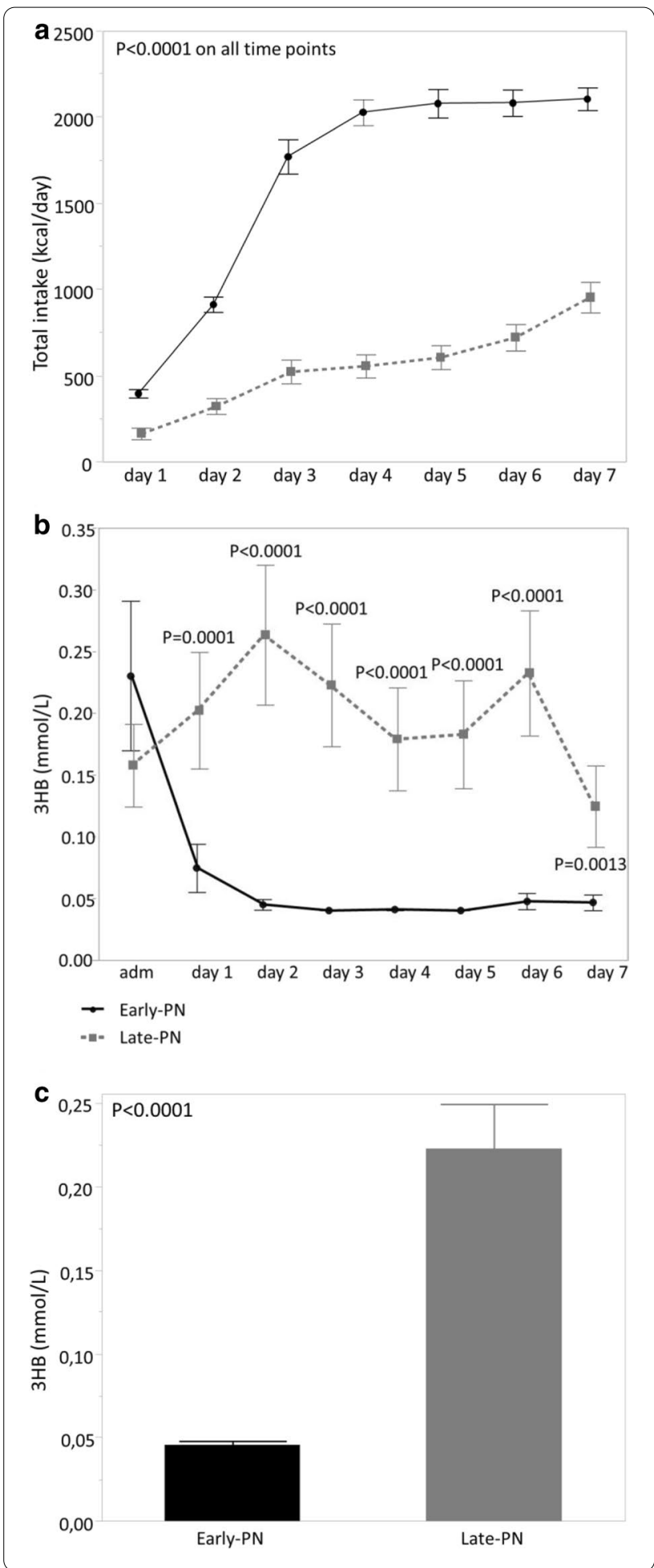

Fig. 1 Total caloric intake (a) and plasma 3HB (b) from admission/ day 1 until day 7 in a matched subset of early-PN patients $(n=55)$ and late-PN patients $(n=55)$ with a surgical contraindication to enteral nutrition, an ICU stay of at least 7 days, and available plasma sample on each day. The groups were propensity score-matched for age, BMI, malignancy, APACHEll score, NRS score, diagnostic group. c Plasma 3HB concentration on day 2 in ICU (or day 1 for 65 patients with a shorter ICU stay) in the total cohort of patients with surgical contraindication to enteral nutrition $(n=509)$. Plasma $3 \mathrm{HB}$ concentrations were significantly higher $(P<0.0001)$ in late-PN than in early-PN patients. Data are shown as means \pm standard errors

We demonstrated that withholding early parenteral nutrition induced ketogenesis in adult ICU patients with a surgical contraindication to enteral nutrition [3]. However, ketone concentrations were only modestly elevated as compared to the much larger effect in critically ill children, and in contrast to critically ill children, plasma $3 \mathrm{HB}$ did not independently associate with enhanced recovery. Also in health, the ketogenic response is known to be more pronounced in children than in adults [4]. Although speculative, this may explain why critically ill children had a more pronounced outcome benefit than adults $[1$, 2]. Also in critically ill children, however, there was no independent association of $3 \mathrm{HB}$ with incidence of infections, which suggests that other mechanisms are involved in outcome protection through late-PN. In this regard, we previously identified increased autophagy as one potential mediator [5]. Of note, especially in early-PN adult patients, a considerable number of $3 \mathrm{HB}$ measurements were assigned the detection limit $(0.04 \mathrm{mmol} / \mathrm{L})$ due to lower concentrations, which may have obscured detecting a mediating role of ketones on outcome.

In conclusion, withholding early parenteral nutrition enhanced ketogenesis in critically ill adults, but in contrast to children, increased ketones did not explain the improved outcome. This suggests clinical benefits of omitting early-PN were mediated through other mechanisms. 
Table 1 Baseline characteristics and outcome of the study patients

\begin{tabular}{|c|c|c|c|}
\hline $\begin{array}{l}\text { EPaNIC patients with surgical contraindication to enteral nutrition and } \\
\text { available plasma }\end{array}$ & Early-PN & Late-PN & P-value \\
\hline Baseline characteristics time cohort $(n=110)$ & $n=55$ & $n=55$ & \\
\hline Age (years)—median (IQR) & $68.1(55.9-77.8)$ & $66.1(55.5-73.6)$ & 0.45 \\
\hline $\mathrm{BMI}$-median $(\mathrm{IQR})^{\mathrm{a}}$ & $25.3(22.2-29.2)$ & $25.7(22.4-33.7)$ & 0.61 \\
\hline Malignancy—no. (\%) & $31(56.3)$ & $32(58.1)$ & 1.00 \\
\hline APACHEIl score-median (IQR) ${ }^{\mathrm{b}}$ & $36(28-39)$ & $35(31-39)$ & 0.75 \\
\hline NRS score-median $(\mathrm{IQR})^{\mathrm{c}}$ & $4(3-6)$ & $4(4-6)$ & 0.49 \\
\hline Diagnostic categories & & & 0.69 \\
\hline (Complications after) abdominal/pelvic surgery—no. (\%) & $36(65.4)$ & $33(60.0)$ & \\
\hline (Complications after) thoracic surgery—no. (\%) & $19(34.5)$ & $22(40.0)$ & \\
\hline Baseline characteristics total cohort $(n=509)$ & $n=252$ & $n=257$ & \\
\hline Age (years)—median (IQR) & $64.4(54.4-73.5)$ & $64.4(53.7-73.0)$ & 0.99 \\
\hline $\mathrm{BMI}$-median $(\mathrm{IQR})^{\mathrm{a}}$ & $24.5(22.2-28.3)$ & $24.6(22.0-28.7)$ & 0.89 \\
\hline Malignancy-no. (\%) & $161(63.8)$ & $154(59.9)$ & 0.36 \\
\hline APACHEIl score-median (IQR) ${ }^{b}$ & $27(16-37)$ & $28(18-36)$ & 0.86 \\
\hline NRS score-median $(I Q R)^{c}$ & $4(3-6)$ & $4(3-5)$ & 0.34 \\
\hline Diagnostic categories & & & 0.70 \\
\hline (Complications after) abdominal/pelvic surgery—no. (\%) & $168(66.6)$ & $177(68.8)$ & \\
\hline (Complications after) thoracic surgery—no. (\%) & $84(33.3)$ & $80(31.1)$ & \\
\hline Outcome of total cohort $(n=509)$ & $n=252$ & $n=257$ & \\
\hline Hazard ratio $(95 \% \mathrm{CI})$ for time to live ICU discharge & & $1.23(1.02-1.48)$ & 0.024 \\
\hline Alive ICU discharge within 8 days—no. (\%) & $125(49.6)$ & $151(58.7)$ & 0.041 \\
\hline New infection-no. (\%) & $103(40.2)$ & $78(29.8)$ & 0.009 \\
\hline
\end{tabular}

Data are presented as frequencies and percentages or medians with interquartile ranges. Fisher's exact test and Kruskal-Wallis test were used to analyze univariable differences between patient groups, as appropriate. Hazard ratio and 95\% confidence interval (Cl) was calculated with the use of Cox proportional-hazard analysis of the effect of late-PN, with adjustment for age, BMI, malignancy, APACHEIl score, NRS score, and diagnostic category

a The body-mass index is the weight in kilograms divided by the square of the height in meters

b Scores on the Acute Physiology and Chronic Health Evaluation II (APACHE II) range from 0 to 71, with higher scores indicating a greater severity of illness

c Scores on Nutritional Risk Screening (NRS) range from 0 to 7, with higher scores indicating a higher risk of malnutrition

Acknowledgements

We thank Michael Casaer for his assistance to validate the ketone measurements before this study.

\section{Authors' contributions}

$A D, J G, L L, G V d B$ conceived and designed the experiments. SVP performed the laboratory experiments. AD, JG, LL, GVdB analyzed the data and wrote the manuscript. All authors read and approved the final manuscript.

\section{Funding}

This project has received funding from the European Research Council (ERC) under the European Union's Horizon 2020 research and innovation program (AdvG 2017-785809) to GVdB and from the Research Foundation Flanders (G.0C78.17N) to GVdB and LL. GVdB and LL received long-term structural research support from the Methusalem Program funded by the Flemish Government (METH14/06). JG received funding from the University Hospitals Leuven (postdoctoral research fellowship by the Clinical Research and Education Council).

\section{Availability of data and materials}

Data sharing is offered under the format of collaborative projects. Proposals can be directed to the corresponding author.

\section{Declarations}

Ethics approval and consent to participate

This is a secondary analysis of the multicenter (Leuven, BE, Hasselt, BE) EPaNIC randomized controlled trial (ClinicalTrials.gov NCT00512122, $n=4640$ ). The institutional ethical review boards of the participating centers approved the study protocol. Written informed consent was obtained from the patients or next of kin.

\section{Consent for publication}

Not applicable.

\section{Competing interests}

The authors declare that they have no competing interests.

Received: 27 January 2021 Accepted: 26 February 2021

Published online: 11 March 2021 


\section{References}

1. Casaer MP, Mesotten D, Hermans G, Wouters PJ, Schetz M, Meyfroidt G, et al. Early versus late parenteral nutrition in critically ill adults. N Engl J Med. 2011;365(6):506-17.

2. Fivez T, Kerklaan D, Mesotten D, Verbruggen S, Wouters PJ, Vanhorebeek I, et al. Early versus late parenteral nutrition in critically ill children. N Engl J Med. 2016;374(12):1111-22

3. De Bruyn A, Gunst J, Goossens C, Vander Perre S, Guerra GG, Verbruggen $\mathrm{S}$, et al. Effect of withholding early parenteral nutrition in PICU on ketogenesis as potential mediator of its outcome benefit. Crit Care. 2020;24(1):536

4. Cahill GF Jr. Fuel metabolism in starvation. Annu Rev Nutr. 2006;26:1-22.
5. Hermans G, Casaer MP, Clerckx B, Guiza F, Vanhullebusch T, Derde S, et al. Effect of tolerating macronutrient deficit on the development of intensive-care unit acquired weakness: a subanalysis of the EPaNIC trial. Lancet Respir Med. 2013;1(8):621-9.

\section{Publisher's Note}

Springer Nature remains neutral with regard to jurisdictional claims in published maps and institutional affiliations.
Ready to submit your research? Choose BMC and benefit from:

- fast, convenient online submission

- thorough peer review by experienced researchers in your field

- rapid publication on acceptance

- support for research data, including large and complex data types

- gold Open Access which fosters wider collaboration and increased citations

- maximum visibility for your research: over 100M website views per year

At BMC, research is always in progress.

Learn more biomedcentral.com/submissions 